\title{
A POSSIBLE CASE OF GENETIC DRIFT IN COLONIES OF THE LAND SNAIL THEBA PISANA
}

\author{
T. G. L. HICKSON* \\ Zoology Department, University of Cope Town
}

Received 28.vii.71

\section{INTRODUCTION}

THE importance of random genetic drift, or sampling drift, in influencing the frequencies of different morphs in animal populations has been debated since Wright's (1931) early paper on the subject. After extensive work in France on the snail Cepaea nemoralis (L.), Lamotte (1952, 1959) concluded that although predation and environmental factors control to some extent the levels of the variable genes in the populations, there is in addition a considerable amount of variation which can be attributed to random factors.

Cain and Sheppard $(1950,1954)$ have shown that selection by predation depends on the plant cover in which the snails are found, and because of this predation differing habitats have populations with differing gene frequencies. They considered that the importance of random factors is negligible, and this view is supported by others (e.g. Cameron, 1969). The importance of environment has been acknowledged by many authors who have either shown a direct relationship between environmental factors and morph frequencies (e.g. Arnold, 1969), or suggested that unidentified changes of environment reacting with the genotypes of the snails determine the morph frequencies which are constant over large areas (Cain and Currey, 1963), or change within small distances (Wolda, 1969).

Goodhart (1963) has pointed out that "to prove that the Sewall Wright effect has been responsible for inter-colony variation, it must be shown that the effective breeding populations have been small enough for sampling errors to have been important, and that the observed variation is not due to differential environmental selection". It is difficult in a natural habitat to ensure that there is no differential environmental selection, and virtually impossible to prove it, but in the present work specimens of Theba pisana were collected from a small area $800 \mathrm{~m} . \times 80 \mathrm{~m}$. and from sites occupied by only one species of plant, in order to reduce the variation of environmental factors to a minimum. Estimation of rate of movement of the snails and consideration of the terrain between colonies show that there is considerable isolation of colonies. Finally, calculations of the sizes of the populations indicate that random factors may indeed be very important in producing the considerable variations in morph frequencies that are found.

\section{Materials AND Methods}

Theba pisana (Müller) is a land snail which was first recorded in South Africa in 1881 (Barnard, 1951) and now occurs in great abundance in local

\footnotetext{
* Present address: Cauldron Barn Farm, Swanage, Dorset.
} 
T. G. L. HICKSON

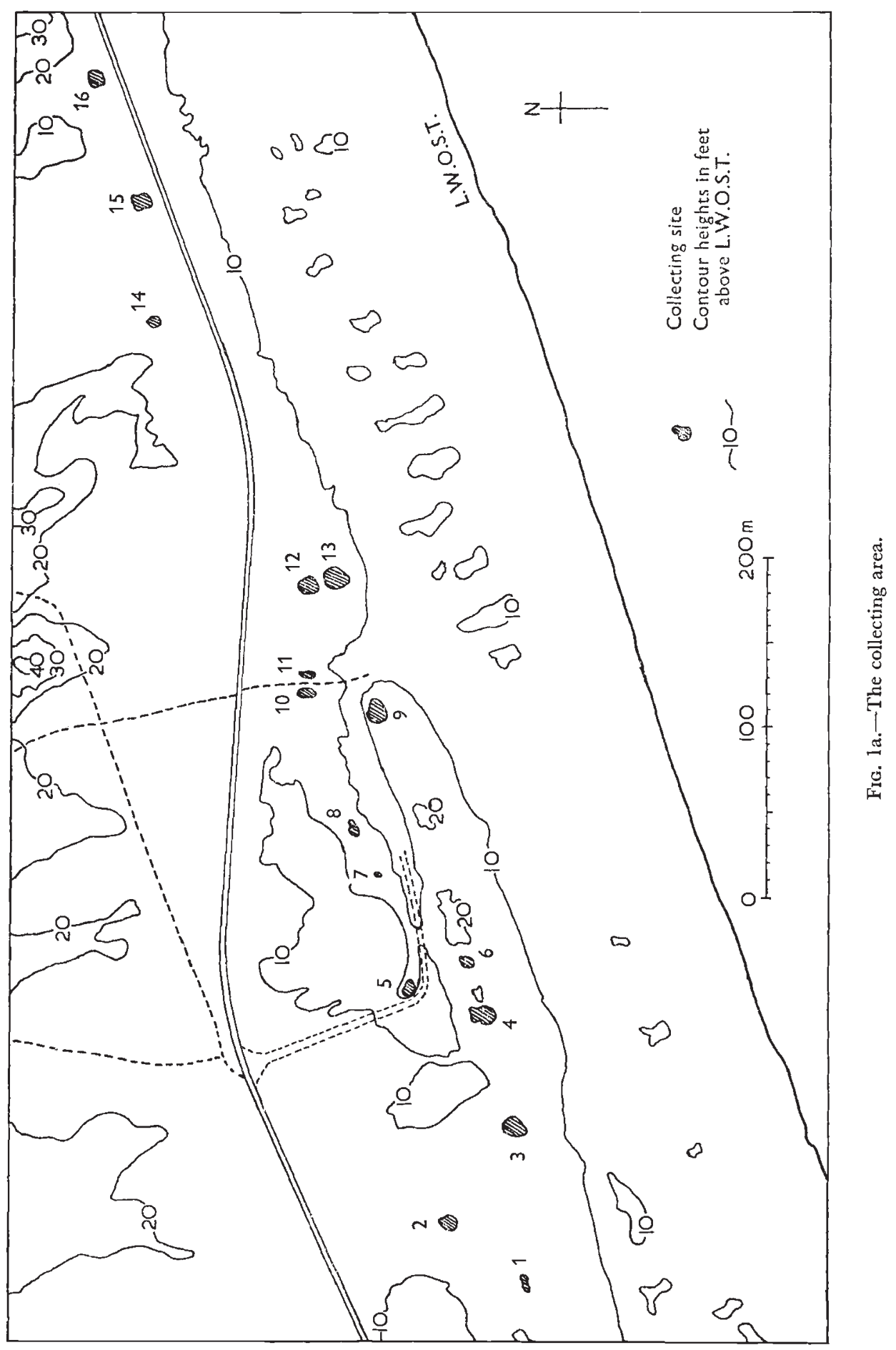



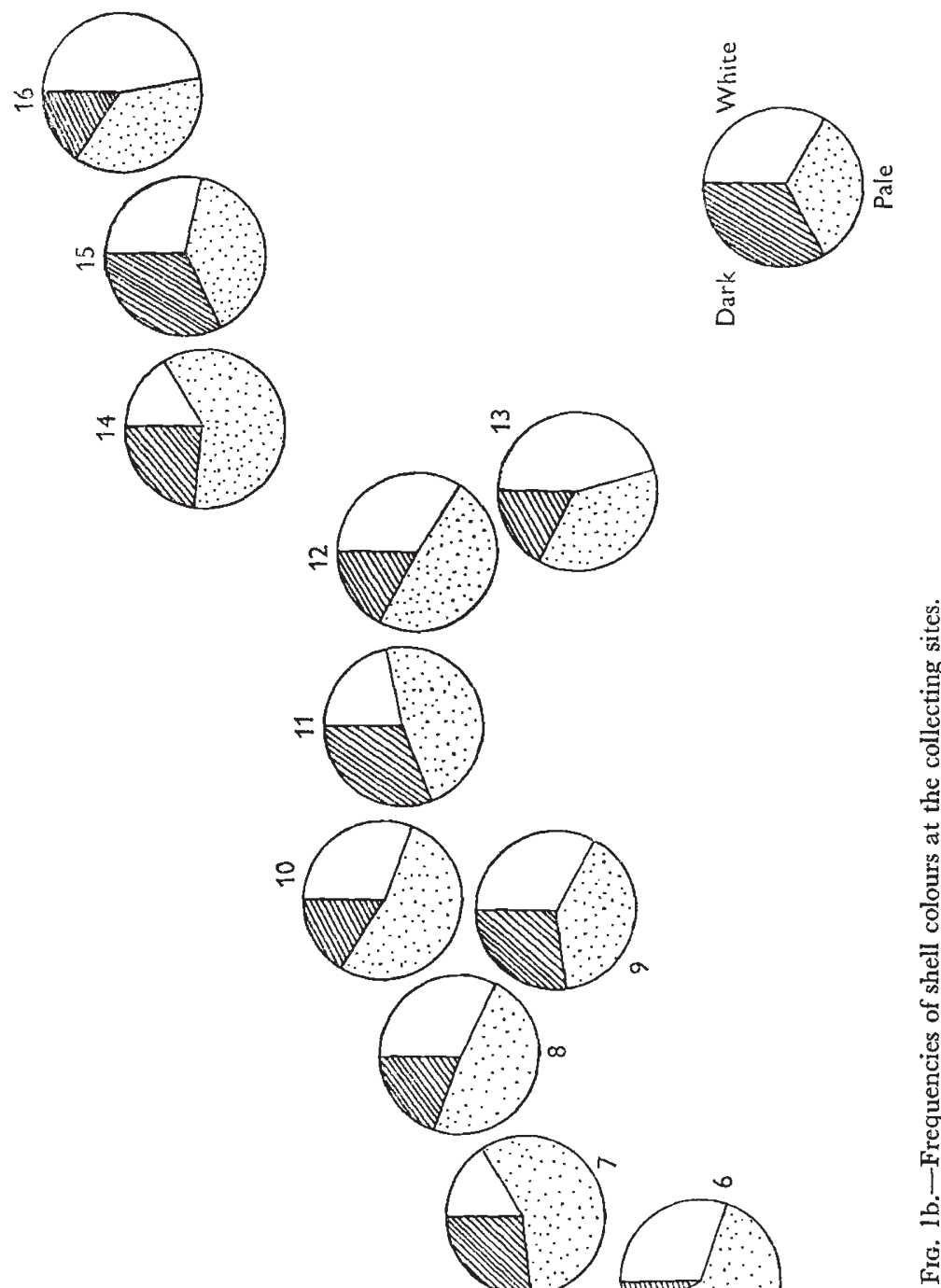

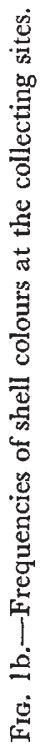

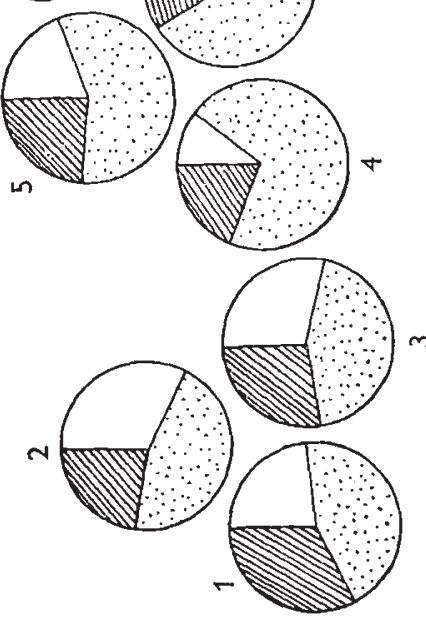


areas of the Western Cape Province. It feeds on a wide range of plants in many different habitats, but for this study the snails were collected only from Tetragonia decumbens Mill. growing on sand dunes along the coast of False Bay, 1 mile north-east of Muizenberg. The area within which all the collecting sites were found extends inland for 70 metres from a line $150 \mathrm{~m}$. from the Low Water of Ordinary Spring Tide position (LWOST), and runs for $800 \mathrm{~m}$. parallel to the coast. In this region the vegetation cover is not continuous and there are islands of vegetation surrounded by sand (plate Ia). T. decumbens forms large clumps in which the stems lie below the surface sending up numerous aerial shoots to an average height of $15 \mathrm{~cm}$. The density of these shoots varies somewhat within the clumps. In order to test whether there is a significant variation from one collecting site to another, a square of wire $25 \mathrm{~cm} . \times 25 \mathrm{~cm}$. was cast at random and the number of shoots within the frame counted. Counts were made in four collecting sites which appeared to show the greatest difference in plant density. Scattered through the clumps are plants of the grass Agropyrum distichum, and in some of them are odd plants of Carpobrotus edulis, Helichrysum crassifolium, Cnidum subfruticosum and Arctotheca populifolia. Snails were only collected from areas where at least 95 per cent. of the plant cover consisted of $T$. decumbens shoots, and there was no additional plant but the grass $A$. distichum. The collecting sites, which are shown in correct scale in fig. $1 \mathrm{a}$, have an average area of $70 \mathrm{~m}^{2}$.

The size of the snail shell may have some influence on the interpretation of its colouring; for example, it appears that many that are initially white, later develop stripes near the mouth of the shell. For this reason only snails that fell within certain size limits were used. The criterion adopted to decide whether or not to accept a shell was the number of whorls present. Only those shells with four to five whorls were accepted (fig. 2).

The predators of $T$. pisana are not known, but as the snail is so abundant and so easy to see (by human standards, see plate II), the effect of any predators cannot be great. It is probable that availability of food, or water during the dry summer months, presence of shade or other factors are more important than predation in limiting population size.

However, in some areas collections of shells were discovered close to burrows of small rodents in dense growth of Acacia cyclops A. Cunn., on which the snails do not normally feed. These shells were without exception broken or gnawed, whereas most empty shells found near the food plant were intact. Thus it was possible to gauge the effect of this rodent predator by comparing the chewed shells with intact ones from a neighbouring clump of $T$. decumbens.

\section{Polymorphism}

The colouring of the shells of $T$. pisana varies in two respects. Firstly there is a wide variation in the striping of the shell. The background colour is white to pale fawn and laid down in this are stripes of brown to black pigment. The stripes are arranged in four longitudinal bands, each band consisting of one to five stripes, or sometimes none. The intensity of colouring of the stripes varies from black to a colour which is just perceptibly darker than the background colour of the shell. Furthermore, the stripes are sometimes interrupted to form a series of discrete dots, of varying size, or they may be fused together to form an undifferentiated broad band. 
As there is such an enormous diversity of striping in the shells, it is necessary to classify them according to some arbitrary definitions. The "white" shells include those that are without pigment, and also shells which have stripes which go less than one whorl around the shell (plate Ib). Those shells that have stripes covering at least the basal whorl are grouped into the "pale" class only if the protoconch is without dark pigment. The " dark" group includes those shells in which the protoconch is dark brown or black. Besides having a darker apex, these shells invariably have the darkest stripes in the collection.

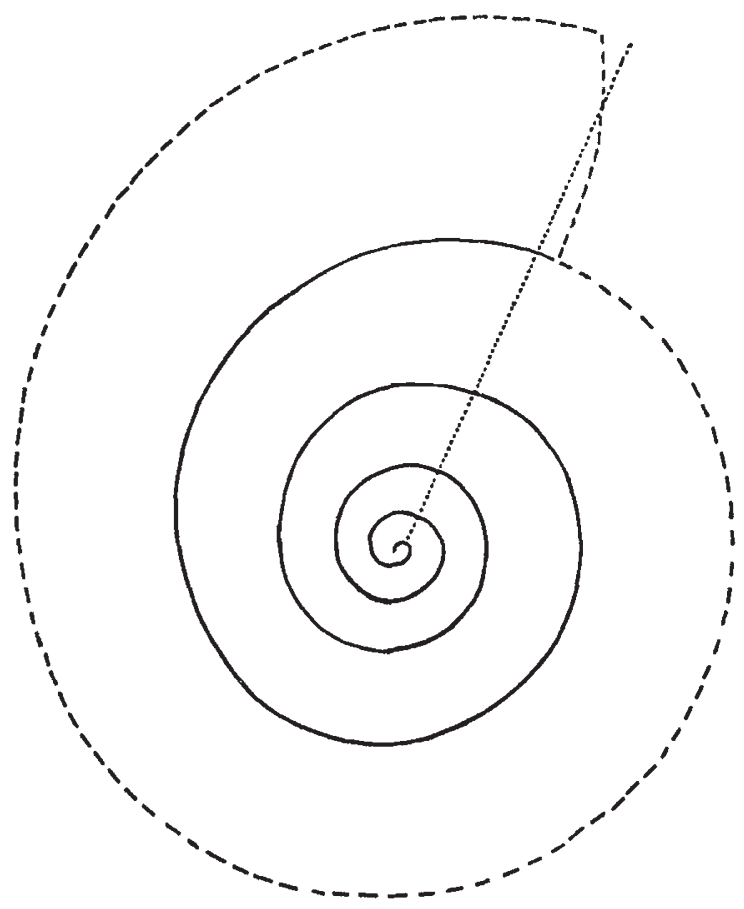

FIG. 2.-Shells were included only if the mouth lay within the position indicated by the dashed line. This was estimated by extending a line directly from the point of the apex, and if it crossed more or less than 4 whorls the shell was discarded.

Secondly, in addition to the striping characteristic, there is variation in the colour of the inner surface of the aperture and the base of the columella, which in some specimens show a rosy pink flush. But as it is difficult to differentiate accurately between different degrees of pinkness this factor has not been considered.

\section{Rate of movement}

A collection of 400 snails from one dune was made and a spot of enamel paint was placed on the shell of each. The marked snails were placed in a line $5 \mathrm{~m}$. long on the dune in the centre of an area with fairly uniform cover of $\mathcal{T}$. decumbens. At weekly intervals the vegetation in the vicinity of the starting-line was searched thoroughly for snails and the distance between each specimen and the starting-line was recorded in centimetres. 


\section{Size of colonies}

The numbers in three colonies were estimated by the mark-releaserecapture technique. The snails were marked as they were clinging to the plants; they were not detached lest this should result in increased mortality. In searching the colonies for snails to mark, an attempt was made to cover the entire area of each colony, so that the painted snails were approximately evenly distributed over the whole colony. An interval of at least a week was allowed for the snails to disperse, then a collection was made, and the snails were scored for presence and absence of paint. The snails were then distributed as evenly as possible over the colony so that they could be collected again subsequently. In one case all the snails collected were again painted, with a different colour, before being scattered. After a period of 17 weeks the paint marks were still visible.

\section{RESULTS}

\section{Comparison between living and dead snails}

In one collecting area a large number of intact shells was collected from the surface of the sand as well as from the stems of the plants, and these were then soaked in water for 24 hours so that the living snails emerged and they could be distinguished from the empty shells. When the bodies of the snails had been removed, the shells were classified (table 1). A $\chi^{2}$ test gave $\chi^{2}=$

TABLE 1

Shells collected from one area and classified according to whether they were alive or dead, and according to the colour

$\begin{array}{lcc} & \text { Alive } & \text { Dead } \\ \text { White } & 19 & 18 \\ \text { Pale } & 85 & 80 \\ \text { Dark } & 25 & 39 \\ \text { Total } & 129 & 137\end{array}$

$3.00,0.20<\mathrm{P}<0.25$; so there is no evidence that the living and dead shells differ with respect to the proportions of the white, pale and dark individuals.

\section{Predated shells}

The gnawed shells collected from near the rodent burrows were compared in a $2 \times 3$ table with shells collected from a nearby patch of $T$. decumbens (table 2); $x^{2}=0.91,0.30<P<0.50$. That is, there was no significant difference between gnawed and intact shells, and it may be concluded from these results that there is no evidence that predation by rodents is influencing the frequencies of the different morphs in the populations.

TABle 2

Shells collected from two adjacent areas, one with gnawed shells, and the other with living snails

$\begin{array}{lcc} & \text { Gnawed shells } & \text { Intact shells } \\ \text { White } & 8 & 18 \\ \text { Pale } & 26 & 41 \\ \text { Dark } & 33 & 47 \\ & & \\ \text { Total } & 67 & 106\end{array}$




\section{Comparisons between different colonies}

Although the sites at which the snails were gathered lay within a small area, and the snails were collected from the same plant species, the proportions of the different colours of shells varied widely. In no case were less than 100 shells collected from any site, so there were sufficient numbers for statistical tests (table 3).

The frequencies of different coloured shells in each colony are shown diagrammatically in fig. $1 \mathrm{~b}$. There is no overall pattern visible, and there is no indication of a cline running through the collecting area.

A test of the overall homogeneity of the 16 different sites with respect to the numbers of white, pale and dark shells was made by calculating $\chi^{2}$ for the $3 \times 16$ table. The very large value obtained $\left(\chi^{2}=132.45, \mathrm{P} \ll 0 \cdot 0005\right)$ confirms that there are significant variations between the sites.

TABLE 3

Counts of snails from different sites

$\begin{array}{ccccc}\text { Site } & \text { White } & \text { Pale } & \text { Dark } & \text { Total } \\ 1 & 30 & 59 & 44 & 133 \\ 2 & 43 & 62 & 31 & 136 \\ 3 & 49 & 75 & 48 & 172 \\ 4 & 11 & 75 & 20 & 106 \\ 5 & 21 & 64 & 27 & 112 \\ 6 & 31 & 63 & 9 & 103 \\ 7 & 18 & 67 & 31 & 116 \\ 8 & 43 & 64 & 26 & 133 \\ 9 & 41 & 49 & 34 & 124 \\ 10 & 33 & 58 & 18 & 109 \\ 11 & 29 & 65 & 42 & 136 \\ 12 & 49 & 70 & 24 & 143 \\ 13 & 56 & 46 & 22 & 124 \\ 14 & 16 & 61 & 24 & 101 \\ 15 & 31 & 44 & 36 & 111 \\ 16 & 55 & 43 & 19 & 117\end{array}$

The densities of $T$. decumbens shoots varies between 8 and 32 shoots per $625 \mathrm{~cm} .^{2}$. An analysis of variance of the results from 10 counts in each of four different collecting sites gave $\mathrm{F}=4 \cdot 6, \mathrm{P}>0.05$. It may be concluded that the variation of density of shoots between different sites is not significantly greater than the variation within the sites.

\section{Rate of movement}

The results from measuring the distance moved by individual snails after 1 week and after 3 weeks from the start of the experiment are shown as histograms in figs. 3 and 4 . The theoretical normal curves derived from the means and the standard deviations of the raw data are also shown. The histograms appear to follow the normal curves quite closely, except that they are leptokurtic in the central values. The degree of kurtosis $(K u)$ is calculated from the formula

$$
\kappa u=\frac{n \Sigma r^{4} f}{\left(\Sigma r^{2} f\right)^{2}} \text { (Dobzhansky and Wright, 1947), }
$$

where $n$ is the number of snails recorded and $f$ is the frequency of the snails reaching a position $r \mathrm{~cm}$. from the starting position. The results of the calculations of $K u$ are entered in table 4 . In a normal curve, $K u=3$. 
This figure is exceeded in the data collected on $13 / 2$ and $20 / 2$, however the test of Pearson (1931) shows that these values for $K u$ are not significantly higher than 3.

TABLE 4

Results of analysis of movements of snails

$\begin{array}{ccccc}\text { Date } & \text { Number of snails } & \text { Variance }\left(\mathrm{m} .{ }^{2}\right) & \begin{array}{c}\text { Variance } \\ \text { increment }\end{array} & K u \\ 6 / 2 / 70 & 400 \text { (start) } & & & \\ 13 / 2 / 70 & 171 & 0.159 & 0 \cdot 159 & 3.55 \\ 20 / 2 / 70 & 161 & 0.231 & 0.071 & 3.65 \\ 27 / 2 / 70 & 173 & 1.052 & 0.821 & 2.97\end{array}$

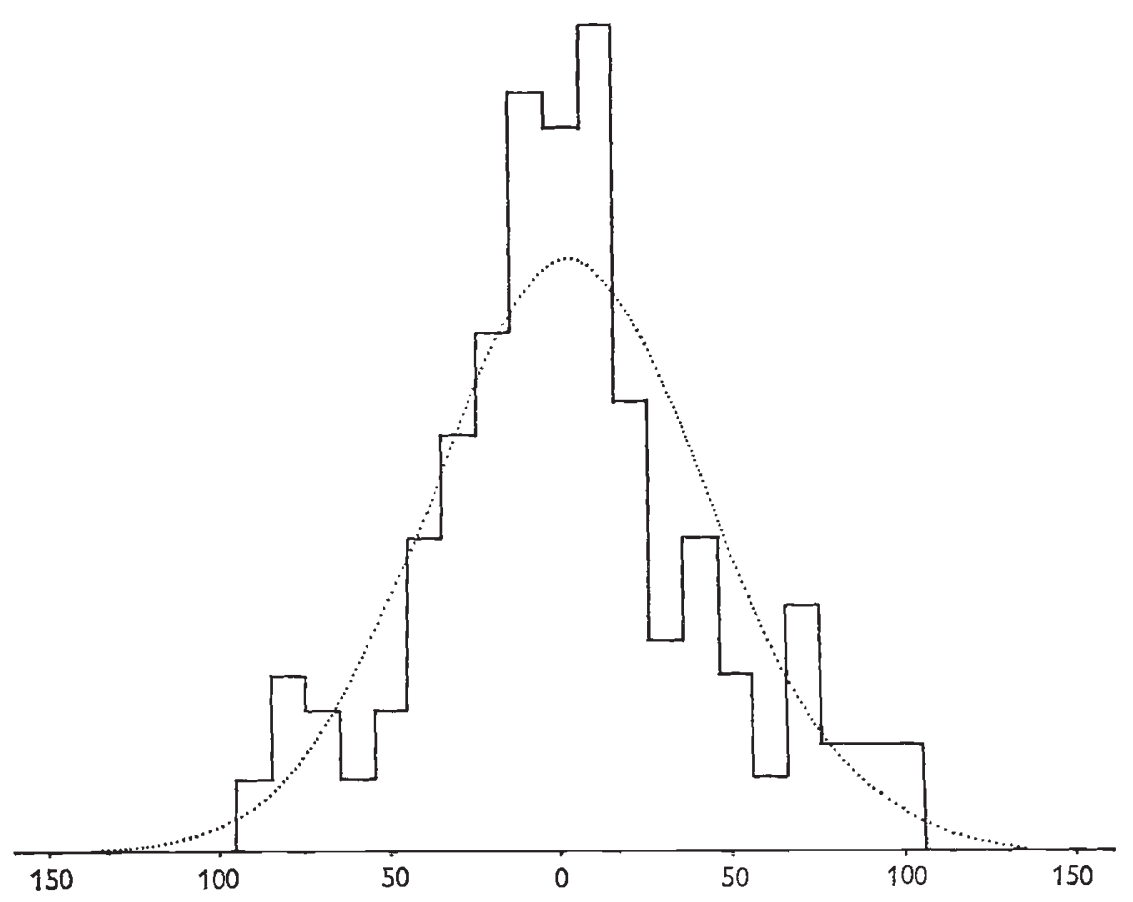

FIG. 3.- Histogram showing distances moved by snails in one week. The distances shown on the abscissa are in $\mathrm{cm}$. The normal curve with the same mean and standard deviation is shown as a dotted line.

The dispersal of animals that are moving at random may be compared to the diffusion of molecules in a solution. The diffusion coefficient of the molecule is found from the expression

$$
D=\frac{\sigma^{2}}{2 t}
$$

and the same expression may be applied to the data of snail dispersion in order to get the "diffusion coefficient" of the snail. In table 5 this has been done for the data of T. pisana and also for Goodhart's (1962) figures, using his fixed mean data. 


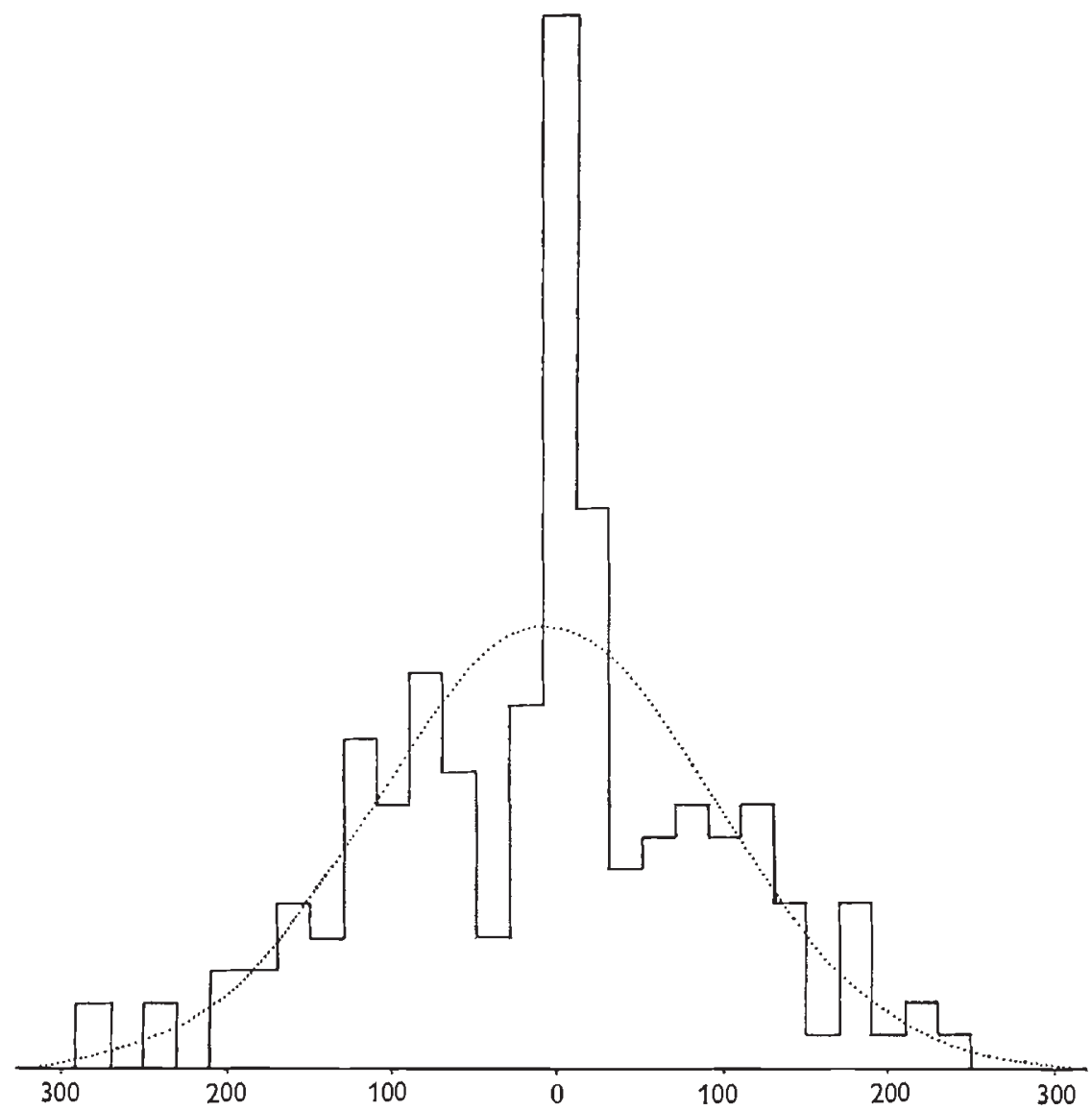

FIG. 4.-Distances moved by snails in 3 weeks.

TABLE 5

Rates of movement of $\mathbf{T}$. pisana and $\mathrm{C}$. nemoralis

Time (weeks)

$$
\text { Theba pisana }
$$

0-1

$1-2$

2-3

0.159

$0 \cdot 071$

0.821

"Diffusion coefficient" $D=\frac{\sigma^{2}}{2 t} \mathrm{~m} \cdot{ }^{2} /$ week

0.079

0.035

0.410

Average $0 \cdot 175$

* Cepaea nemoralis

$0-4$

4-14

$4 \cdot 01$

$2 \cdot 09$

0.501

$0 \cdot 104$

$14-51$

$4 \cdot 27$

Average 0.221

* Data taken from Goodhart (1962). 
It may be seen that the average "diffusion coefficient" for $T$. pisana is $0.17 \mathrm{m.} .^{2} /$ week and for $C$. nemoralis it is $0.22 \mathrm{~m} .{ }^{2} /$ week. $T$. pisana is a slightly smaller snail although this probably has no bearing on their relative speeds.

The magnitude of the variances recorded for $T$. pisana in table 5 may be correlated with the rainfall. During the first week of investigation rain fell for about 12 hours and the variance is $0.16 \mathrm{~m}^{2}$; in the second week no rain fell, giving a low variance of $0.07 \mathrm{~m} .{ }^{2}$, and the third week included 36 hours of intermittent rain giving a variance of $0.82 \mathrm{~m} .{ }^{2}$. The movement of the snails is clearly influenced by the periods of rain. Thus the figure calculated for the "diffusion coefficient" is an approximate one calculated over 3 weeks of the relatively dry summer. The movement in the wet winter months of the Cape Province may be more rapid, though Goodhart's (1962) figures reflect slower movements in the English winter because of the lower temperatures.

\section{Size of colonies}

Three sites were chosen for estimation of snail numbers. From experience in collecting it was known that one site (9) had an abundance of snails over a comparatively large area, and the other two sites (6 and 10) had far fewer snails. The results of the counts of the painted snails are entered in table 6 .

TABLE 6

Numbers of snails painted and re-collected at three sites

\begin{tabular}{crrrrrrrr} 
Site & \multicolumn{1}{c}{ Date } & No. & & Painted & Marked & Unmarked & Total & $\begin{array}{c}\text { Estimated } \\
\text { total No. }\end{array}$ \\
6 & $13 / 3 / 70$ & 108 & $16 / 6 / 70$ & 5 & 80 & 85 & 1836 \\
9 & $6 / 2 / 70$ & 300 & $13 / 3 / 70$ & 47 & 890 & 937 & 5981 \\
& $6 / 2 / 70$ & 300 & $16 / 6 / 70$ & 17 & 417 & 434 & 7659 \\
10 & $13 / 3 / 70$ & 937 & $16 / 6 / 70$ & 80 & 354 & 434 & 5083 \\
& $6 / 2 / 70$ & 53 & $13 / 2 / 70$ & 8 & 44 & 52 & 344 \\
& $6 / 2 / 70$ & 53 & $13 / 3 / 70$ & 18 & 112 & 130 & 383 \\
& $6 / 2 / 70$ & 53 & $16 / 6 / 70$ & 3 & 46 & 49 & 866
\end{tabular}

The final column has been estimated from the relationship:

Total number in population $=\frac{\text { Number painted } \times \text { Total number collected }}{\text { Number of painted shells collected }}$

(Jackson, 1936, p. 848). It may be noted that the estimates for sites 9 and 10 are higher when the snails were marked on 6/2/70 and collected on $16 / 6 / 70$. This is probably due to the fact that some of the marked snails died or migrated away or for some other reason disappeared in the long interval between these two dates, thus resulting in an estimate that is too high. In order to get a more accurate estimate of the populations, the figures were corrected as described by Jackson (1936, p. 852) and the logs plotted. Extrapolation of the curves to zero time gave estimated populations of 5500 at site 9 and 300 at site 10 . The areas of these sites are $168 \mathrm{~m}^{2}$ and $50 \mathrm{~m} .^{2}$ respectively, so the concentrations of snails are 33 snails per $\mathrm{m}^{2}$ and 6 snails per m. $^{2}$. As these sites were chosen because they appeared to show extremes of snail density, these figures may be taken as the limits of variability of snail concentration for estimating the probable populations at other sites. The results are shown in table 7 . 
TABLE 7

\begin{tabular}{cccc}
\multicolumn{3}{c}{ Size of colonies } \\
Site & $\begin{array}{c}\text { Dimensions } \\
(\mathrm{m} .)\end{array}$ & Area $\left(\mathrm{m}^{2}\right)$ & $\begin{array}{c}\text { Populations estimated from snail } \\
\text { densities of } 6 \text { and } 33 \text { snails } / \mathrm{m}^{2}{ }^{2}\end{array}$ \\
1 & $10 \times 4$ & 40 & $240-1320$ \\
2 & $9 \times 7$ & 63 & $380-2080$ \\
3 & $12 \times 15$ & 180 & $1080-5940$ \\
4 & $12 \times 14$ & 168 & $1000-5540$ \\
5 & $10 \times 5$ & 50 & $300-1650$ \\
6 & $8 \times 8$ & 64 & 1800 \\
7 & $5 \times 4$ & 20 & $120-600$ \\
8 & $10 \times 5$ & 50 & $300-1650$ \\
9 & $12 \times 14$ & 168 & 5500 \\
10 & $10 \times 5$ & 50 & 300 \\
11 & $8 \times 5$ & 40 & $240-1320$ \\
12 & $11 \times 10$ & 110 & $660-3630$ \\
13 & $14 \times 12$ & 168 & $1000-5540$ \\
14 & $7 \times 6$ & 42 & $250-1390$ \\
15 & $12 \times 8$ & 96 & $580-3170$ \\
16 & $10 \times 10$ & 100 & $600-3300$
\end{tabular}

\section{Discussion}

The frequencies of the characteristics studied vary widely from one sample of snails to another. The probability that the samples are from a homogeneous population is much less than 0.05 per cent., thus the variation evident in the samples reflects a very real variation in the populations from which they were drawn.

Cain and Sheppard (1950) have shown that the variation in morph frequencies of Cepaea nemoralis in different colonies is produced, in part at least, by the differential bird predation to which the morphs are subjected in different environments. It is not known whether birds eat $T$. pisana, but if they do it would be expected that the predation would not vary between colonies investigated as they were all found on the same species of plant. Predation by a small burrowing animal, probably a rodent, has been noted, but this is not selective with respect to the striping categories. In this respect the predation is similar to that of rodents on $C$. nemoralis as shown by Day and Dowdeswell (1968), though these authors point out that larger numbers might have shown a significant selective action.

A difference in environment between one colony and another could also change morph frequencies. Arnold (1969) has shown that riverside and hillside populations of $C$. nemoralis show different morph frequencies; altitude and proximity to the river may be contributing factors. In this study, however, all the colonies were found between the 10- and 20-ft. contours, so altitude must be of little significance. Distance from the sea could be of importance to snails, as spray and mists are carried in from the sea during the summer by the prevailing S.E. winds. But the 16 colonies lie in a belt only $70 \mathrm{~m}$. wide between 150 and $220 \mathrm{~m}$. from the LWOST line, so that distance from the sea is probably less important than local differences in micro-climate caused by other factors. These factors are difficult to analyse, and would include the exact configuration of the nearby dunes and their effect on the winds, the density of the plant cover and the angle of exposure of the dune to the sun. The strengths of the winds can not be measured and are probably so variable as to be unimportant. Although the plant shoots 
vary somewhat in length and number of leaves the results of counting shoots do give an approximation of the density of the plants, and the results tend to confirm the subjective impression that there is greater variation of plant density within the collecting sites than between them. The angle of exposure varies within each site as most sites are rounded and all show many aspects, which change as the sands drift, thus it is unlikely that this factor is of importance in influencing shell colour frequencies.

Before assuming that the variation in populations is due to random sampling errors it is necessary to consider whether the characteristics concerned are genetically controlled, whether there is sufficient isolation between the colonies to allow random drift to take effect, and whether the colonies are small enough for sampling errors to have been important.

The banding patterns of $C$. nemoralis have been demonstrated to be genetically controlled (e.g. Wolda, 1969) and similar inheritance has been found in C. hortensis by Murray (1963). By analogy it is almost certain that the striping of $T$. pisana is also a hereditary feature, though no work has been reported on the genetics of this snail.

The rate of movement of the snails was measured in vegetation, and the " diffusion coefficient" found to be $0.17 \mathrm{~m} .{ }^{2} /$ week. This estimate is only approximate as the amount of movement is influenced by the rainfall and probably by other factors affecting humidity. However, if this figure is accepted then $\sigma$ for 1 year is $4.2 \mathrm{~m}$., that is about 30 per cent. of the snails will move this distance or more in 1 year. The distance between some colonies is as little as $50 \mathrm{~m}$. but it would take about 35 years for 5 per cent. of the population to travel this distance, assuming the above diffusion coefficient to be accurate. Obviously individual snails would only travel a small part of this distance, but if the genotype does not influence the rate of movement the above figures would apply to 5 per cent. of the genotypes.

The measurements of speed of movement were made in vegetation, but when a snail finds itself on a bare patch of sand it will travel very much faster than in plant cover, and its movement will be more directional, thus the dispersal from one colony to another may be more rapid than indicated above. However, the figures do give some indication of the order of time involved and show that even the closest colonies are relatively isolated from one another.

Dobzhansky and Wright (1947), in their study of the speed of movement of a mutant, found that there was considerable kurtosis of the distribution curve, with values of $K u$ up to $13 \cdot 0$. This was due to heterogeneity of the dispersal movements of the flies. Bateman (1950) has also shown that different forms of gene dispersal tend to show leptokurtic distributions. The histograms of figs. 3 and 4 also show the same type of distribution, even though values of $K u$ are found to be not significantly different from 3 .

The densities of $C$. nemoralis were found by Cain and Currey (1967) to average 0.6 snail $/ \mathrm{m} .{ }^{2}$ in grassland and 8 snails $/ \mathrm{m} .{ }^{2}$ in neighbouring nettle patches. Estimation of densities in sparsely populated and in thickly populated colonies of $T$. pisana give 6 snails $/ \mathrm{m}^{2}{ }^{2}$ and 33 snails $/ \mathrm{m} .{ }^{2}$. If it is assumed that the other colonies sampled had densities of snails intermediate between these values then table 7 shows that many colonies had 1000 or fewer individuals. Many colonies in the field were not sampled because the density of snails was so low that an adequate sample of snails could not be collected readily, and the total number of individuals in such colonies must 
Plate I

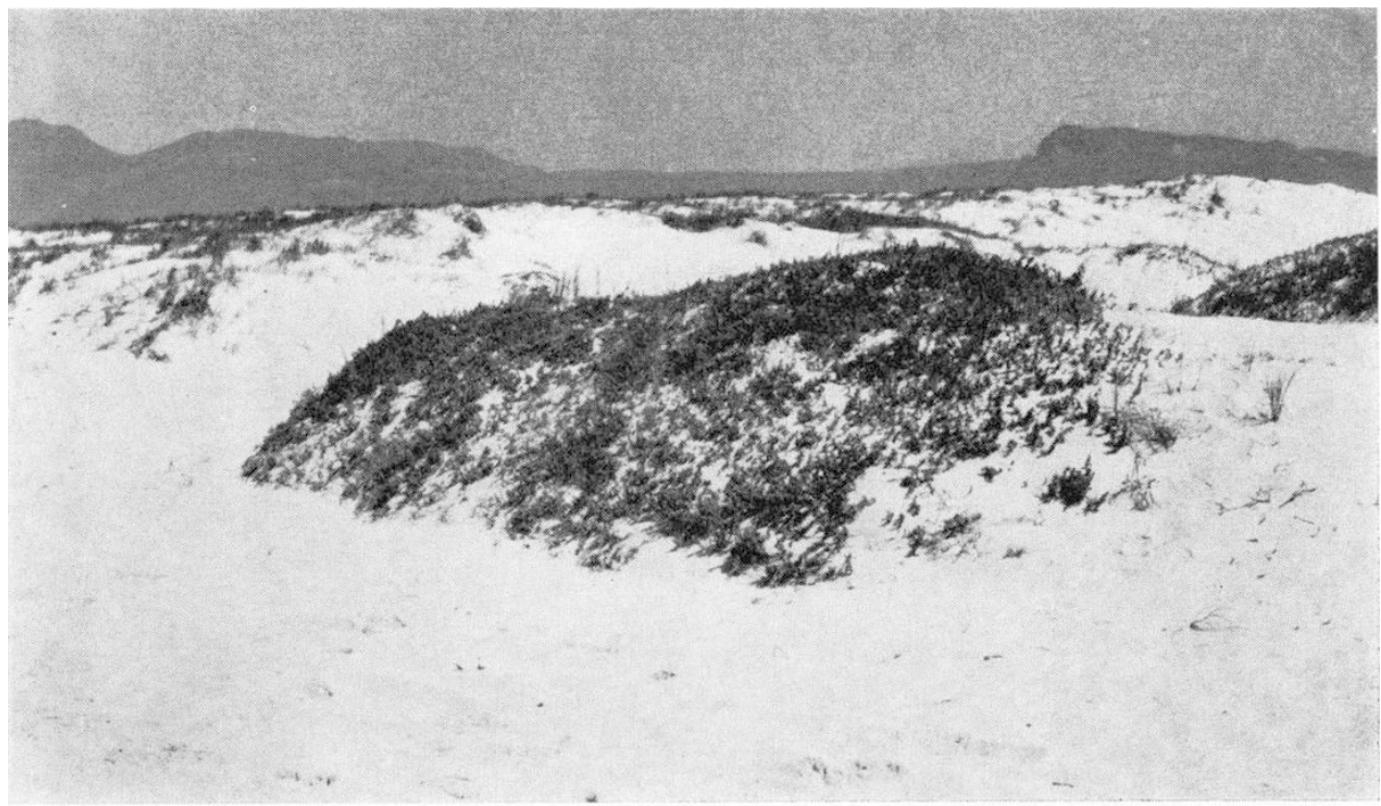

Plate Ia.-Collecting site No. 10. Most of the plant cover visible is Tetragonia decumbens.

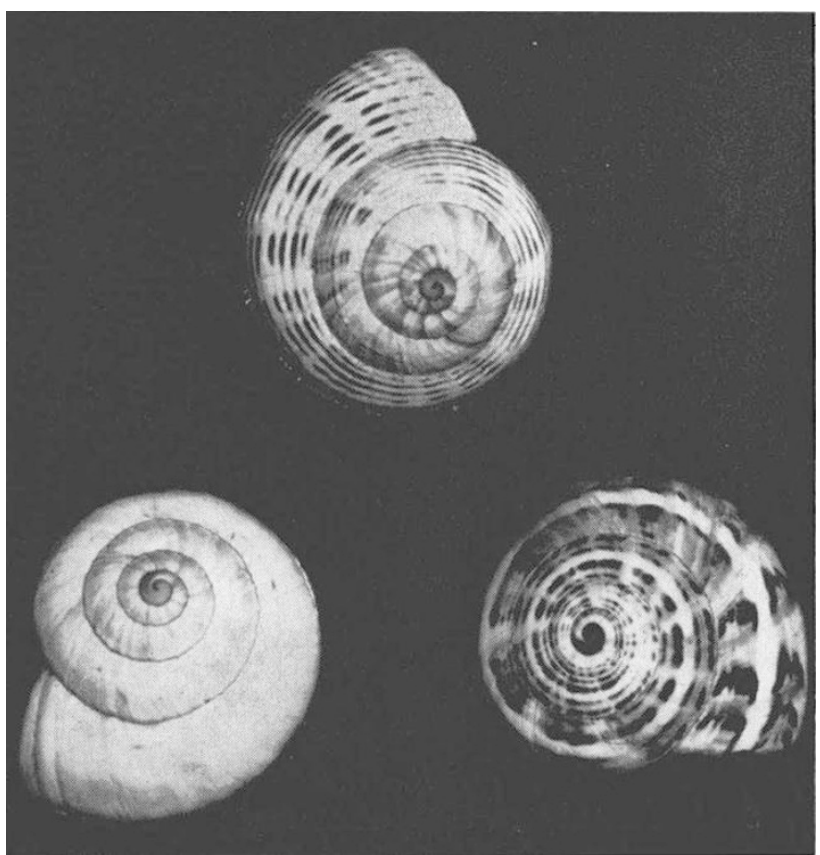

Plate Ib.--Variation in shell striping. Left: "white"; top: "pale"; right: "dark", 
Plate II

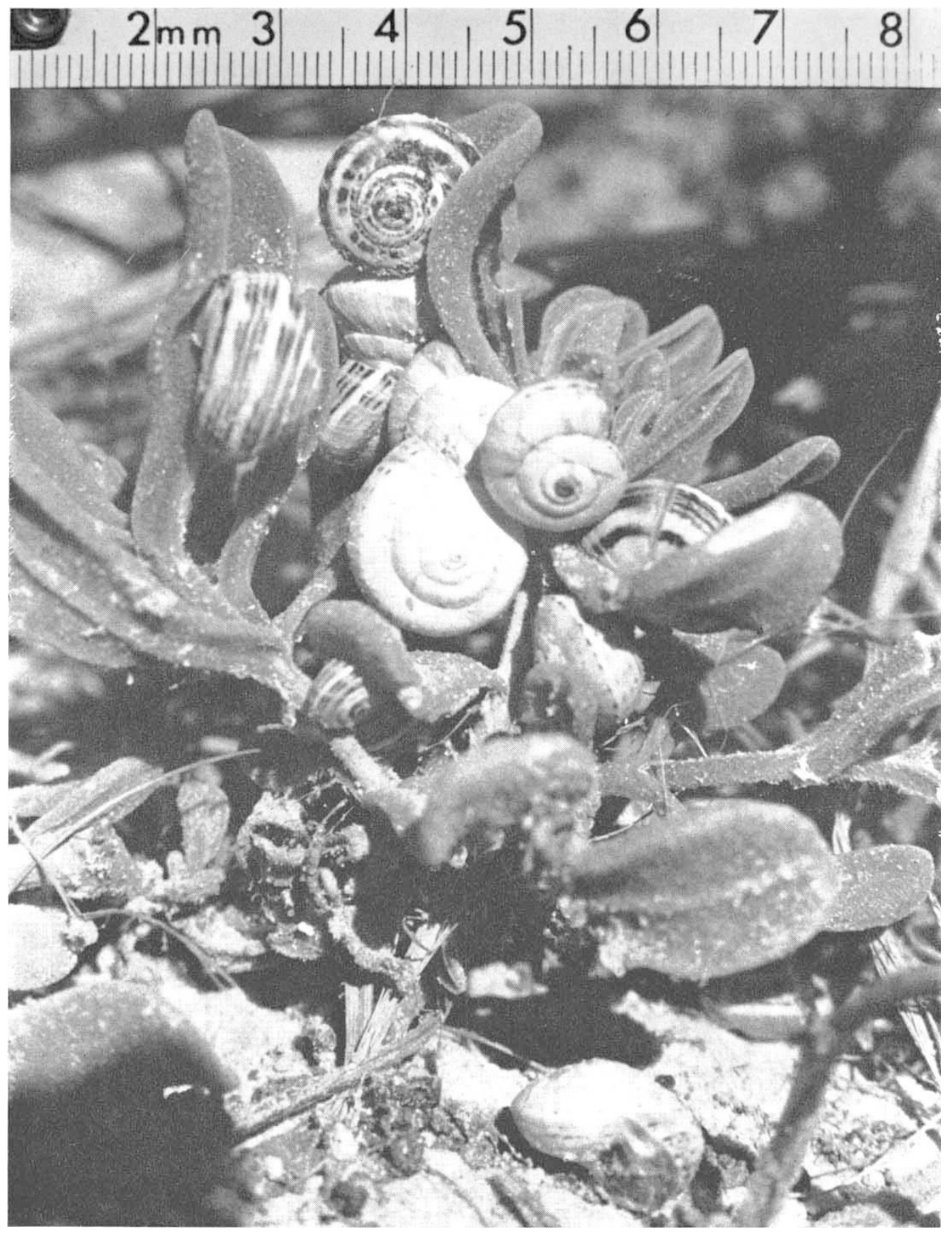

Specimens of $T$. pisana in situ on a twig of $T$. decumbens. 
have been small. Probably a colony starts with a few founding members and then increases and decreases in size, corresponding with the success of the host plant and the waxing and waning of the size of the dune on which it is situated.

The small number of individuals in each colony, at least at some stages of colony history, and the relative isolation of these colonies, would seem to be features which are ideal for the demonstration of the change of populations by random sampling errors. This may either be a continuous process resulting in "Sewall Wright drift" or may be effected by the survival from time to time of "Founder stock". As has been pointed out by Wright (1959), mathematically the latter is a particular case of the former and the effects would be virtually indistinguishable. The conclusion that random effects are responsible for the considerable diversity of frequencies of morphs of Theba pisana is strengthened by the facts that no differential predation can be demonstrated nor can any continuing selective effect of the environment be shown.

\section{SUMmary}

1. Populations of Theba pisana (Müller) found on sand dunes have been analysed according to the striping of the shell.

2. Significant differences have been found between many of the colonies for the frequencies of this character.

3. Predation by a rodent has been investigated and it has been shown that there is no differential predation for the striping character.

4. The snails were all taken from the same plant species, and the colonies were within a small homogeneous area so it is considered unlikely that environment is having an effect on morph frequencies.

5. No consistent overall change of frequencies of morphs is noted within the collecting area.

6. The "diffusion coefficient" within an area of vegetation was found to be approximately $0.17 \mathrm{m.} /$ week, but this measurement is greatly influenced by the rainfall. This slow rate of movement indicates that the colonies are relatively isolated from each other.

7. The distribution curve of the movement of the snails within the vegetation follows fairly closely the theoretical normal curve, with some kurtosis evident.

8. The populations of two colonies have been found to contain 300 and 1800 individuals respectively. The densities of the snails in these colonies were 6 and 33 snails $/ \mathrm{m}^{2}$. Using these figures, the populations of the colonies sampled were estimated to vary between approximately 200 and 5000 individuals.

9. In the absence of any evidence to show that the shell-striping character has been selected by a predator or by environment, and as the colonies are comparatively isolated and often contain quite low numbers, it is suggested that random sampling errors are the cause of the very different frequencies in the different populations.

Acknowledgment.-My thanks are due to Professor J. Day for suggesting the subject of this paper. 


\section{REFERENCES}

ARNOLD, R. 1969. The effects of selection by climate on the land snail Cepaea nemoralis (L.). Evolution, 23, 370-378.

BARnARD, к. H. 1951. A Beginner's Guide to South African Shells. Maskew Miller, Cape Town.

BAtEMAN, A. J. 1950. Is gene dispersal normal? Heredity, 4, 353-363.

CAIN, A. J. AND CURREY, J. D. 1963. Area effects in Cepaea on the Larkhill artillery ranges, Salisbury Plain. 7. Linn. Soc. (Zool.), 45 (303), 1-15.

CAIN, A. J. AND CuRREY, J. D. 1967. Studies on Cepaea. III. Ecogenetics of a population of Cepaea nemoralis (L.) subject to strong area effects. Phil. Trans. Roy. Soc. London (B), $253,447-482$.

CAIN, A. J. AND SHEPPARD, P. M. 1950. Selection in the polymorphic land snail Cepaea nemoralis. Heredity, 4, 275-294.

CAIN, A. J. AND SHEPPARD, P. M. 1954. Natural selection in Cepaea. Genetics, 39, 89-116.

CAMERON, R. A. D. 1969 . The distribution and variation of three species of land snail near Rickmansworth, Hertfordshire. Zool. 7. Linn. Soc., 48, 83-111.

DAY, J. C. L. AND DOWDESWELL, w. H. 1968. Natural selection in Cepaea on Portland Bill. Heredity, 23, 169-188.

DOBZHANSKY, T. AND WRIGHT, s. 1947. Genetics of natural populations. XV. Rate of diffusion of a mutant gene through a population of Drosophila pseudoobscura. Genetics, $32,303-324$.

goodhart, c. B. 1962. Variation in a colony of the snail Cepaea nemoralis. F. Animal Ecology, 31, 207-237.

GOODHART, C. B. 1963. "Area effects" and non-adaptive variation between populations of Cepaea (Mollusca). Heredity, 18, 459-465.

JACKson, C. H. N. 1936. Some new methods in the study of Glossina morsitans. Proc. Zool. Soc. Lond.

LAMOTтE, M. 1952. Le rôle des fluctuations fortuites dans la diversité des populations naturelles de Cepaea nemoralis (L.). Heredity, 6, 333-343.

Lамотте, м. 1959. Polymorphism of natural populations of Cepaea nemoralis. Cold Spr. Harb. Symp. Quant. Biol., 24, 65-86.

MURRAY, J. 1963. The inheritance of some characters in Cepaea hortensis and Cepaea nemoralis (Gastropoda). Genetics, 48, 605-615.

PEARSON, E. S. 1931. A further development of tests for normality. Biometrika, 22, 239-249. WOLDA, H. 1969. Fine distribution of morph frequencies in the snail Cepaea nemoralis near Groningen. 7. Animal Ecology, 38, 305-327.

WRIGHT, s. 1931. Evolution in Mendelian populations. Genetics, 16, 97-159.

WRIGHT, s. 1959. In discussion of Lamotte, M., Polymorphism of natural populations of Cepaea nemoralis. Cold Spr. Harb. Symp. Quant. Biol., 24, 65-86. 